\title{
PENDOKUMENTASIAN ASUHAN KEPERAWATAN OLEH PERAWAT PELAKSANA SETELAH DILAKUKAN PELATIHAN SUPERVISI KEPALA RUANG DI RUMAH SAKIT X, KOTA AMBON
}

\section{[DOCUMENTATION OF NURSING CARE BY NURSES AFTER SUPERVISION TRAINING FOR HEAD NURSES ET X HOSPITAL AMBON CITY]}

\author{
Feby Manuhutu ${ }^{1}$, Regina VT. Novita ${ }^{2}$, Sudibyo Supardi ${ }^{3}$ \\ Program Pasca Sarjana STIK Sint Carolus Jakarta ${ }^{1,2}$ \\ Badan Litbangkes Kemenkes RI ${ }^{3}$ \\ e-mail : feby.manuhutu191212@gmail.com \\ DOI : 10.47718/jpd.v8i01.1150
}

\section{ABSTRAK}

\begin{abstract}
Latar Belakang: Rumah sakit sebagai pemberi jasa layanan kesehatan dituntut untuk memberikan layanan yang berkualitas. Pelayanan yang berkualitas dapat diwujudkan melalui dokumentasi berupa catatan perawatan klien. Dokumentasi asuhan keperawatan harus dilakukan dengan baik untuk memastikan keamanan dan kualitas pelayanan kesehatan. proses asuhan keperawatan telah dilakukan dengan baik oleh perawat pelaksana, tetapi untuk proses dokumentasi masih sangat kurang. Kelengkapan dokumentasi pada proses asuhan keperawatan kurang dari 50\%. Supervisi kepala ruang sebagai first line manager di RS X Kota Ambon pada pendokumentasian asuhan keperawatan tidak optimal karena belum adanya pelatihan. Tujuan: untuk mengetahui dokumentasi asuhan keperawatan oleh perawat pelaksana setelah pelatihan supervisi kepala ruang di Rumah Sakit X Kota Ambon. Metode: Metode penelitian pra-eksperimental one group pretest post-test design. Jumlah sampel dalam penelitian ini sebanyak 40 responden. Hasil: Hasil Penelitian menunjukkan pelatihan supervisi kepala ruang, dan pendampingan implementasi supervisi selama 1 minggu dapat meningkatkan skor pendokumentasian asuhan keperawatan (pengkajian, diagnosis, intervensi, implementasi, dan evaluasi) secara bermakna ( $p<$ $0.050)$. Tidak ada hubungan antara antara umur $(p=1.926)$, Jenis kelamin $(p=0.943)$, Pendidikan $(p=0.173)$, dan lama kerja $(p=0.195)$ dengan pendokumentasian asuhan keperawatan setelah pelatihan supervise kepala ruang di Rumah Sakit X Kota Ambon. Kesimpulan dan Saran: Rentang usia perawat $20-40$ tahun $(77.5 \%)$, jenis kelamin perempuan $(82,5 \%)$, pendidikan D3/S1 Keperawatan (82,5\%) dan lama kerja lebih dari 6 tahun (65\%). Skor pendokumentasian meningkat secara bermakna $(p<0.050)$ setelah dilakukan pelatihan supervisi kepala ruang, dan pendampingan implementasi
\end{abstract}




\section{ABSTRACT}

supervisi. Tidak ada hubungan antara antara umur $(p=1.926)$, Jenis kelamin $(p=0.943)$, Pendidikan $(p=0.173)$, dan lama kerja $(p=0.195)$ dengan pendokumentasian asuhan keperawatan setelah pelatihan supervisi kepala ruang di Rumah Sakit X Kota Ambon. Penelitian ini merekomendasikan intensitas supervisi kepala ruang harus dipertahankan dan dilakukan secara teratur serta berkelanjutan agar perawat pelaksana dapat temotivasi dalam meningkatkan pendokumentasian yang berorientasi pada pelayanan asuhan keperawatan yang berkualitas

Kata Kunci: Pendokumentasian Asuhan Keperawatan, Pengkajian, Diagnosis, Intervensi, Implementasi, Evaluasi, Supervisi Kepala Ruang

Background: Hospitals as health service providers are required to provide quality services. Quality service can be realized through documentation in the form of client care records. Nursing care documentation must be done properly to ensure the safety and quality of health services. The nursing care process has been carried out well by the implementing nurse, but the documentation process is still lacking. The completeness of documentation in the nursing care process is less than 50\%. Supervision of the head of the room as the first line manager at RS X Ambon City in documenting nursing care was not optimal because there was no training. Aims : to find out the documentation of nursing care by the nurse executing after the training in the supervision of the head of the room at Hospital $X$ Ambon CityMethods. Method: The method of pre-experimental research one group pre-test post-test design. The number of samples in this study were 40 respondents. Result: The results showed that training in the supervision of the head of the room, and assistance in implementing supervision for 1 week could significantly increase the score of nursing care documentation (assessment, diagnosis, intervention, implementation, and evaluation) significantly ( $p<0.050)$. There was no relationship between age $(p=1,926)$, gender $(p=0.943)$, education ( $p=0.173)$, and length of work $(p=0.195)$ with documentation of nursing care after training in supervise headroom at Hospital X Ambon City. Conclusion: The age range of nurses was 20-40 years (77.5\%), female gender (82.5\%), D3 / S1 Nursing education (82.5\%) and work duration more than 6 years (65\%). The score for documentation increased significantly $(p<0.050)$ after training on the supervision of the head of the room, and assistance in implementing 
supervision. There was no relationship between age $(p=1,926)$, gender $(p=0.943)$, education $(p=0.173)$, and length of work $(p=0.195)$ and documentation of nursing care after training in the supervision of the head of room at Hospital X Ambon City.

Keywords: Nursing Documentation, Assessment, Diagnosis, Intervention, Implementation, Evaluation, Supervision of Head Nurses.

\section{PENDAHULUAN}

Undang-Undang Republik Indonesia No. 44 Tahun 2009 tentang Rumah Sakit menjelaskan bahwa "Pelayanan kesehatan merupakan hak setiap orang yang dijamin dalam Undang-Undang Dasar Negara Republik Indonesia Tahun 1945 yang harus diwujudkan dengan upaya peningkatan derajat kesehatan masyarakat yang setinggi-tingginya." Rumah sakit sebagai pemberi jasa layanan kesehatan dituntut untuk memberikan layanan yang berkualitas.

Ada kalanya rumah sakit sebagai lembaga layanan kesehatan dihadapkan dengan tantangan, diantaranya kesalahan medis di rumah sakit yang diasumsikan merupakan kesalahan perawat dalam mengikuti instruksi medikasi klien, adanya manajemen resiko dan tindakan hukum yang dibawa ke pengadilan yang memberikan tekanan (McEachen \& Keogh, 2018). Tantangan dalam layanan kesehatan yang dihadapi di rumah sakit dapat dilakukan oleh perawat yang berperan sebagai manajer dengan memanfaatkan fungsi manajemen keperawatan (Swansburg, 2000). Fungsi pengarahan merupakan salah satu cara yang dapat digunakan dalam upaya pencegahan dan pengendalian masalah di area keperawaatan (Robbins \& Judge, 2015). Kegiatan supervisi dilakukan oleh seorang 
supervisor di ruang perawatan yaitu kepala ruang perawatan sebagai first line manager dimana memiliki tanggung jawab dalam memberikan pelayanan kesehatan yang berkualitas dengan biaya yang efektif (McEachen \& Keogh, 2018).

Pendokumentasian asuhan keperawatan sangat penting karena mencerminkan peran perawat dalam memberikan pelayanan kesehatan yang berkualitas (Alkouri, AlKhatib, \& Kawafhah, 2016). Nakate, Dahl, Petrucka, B. Drake, \& Dunlap (2015), dalam penelitiannya menjelaskan bahwa perawat pada rumah sakit pemerintah maupun swasta di Uganda memiliki masalah dalam mendokumentasikan asuhan keperawatan, sehingga penelitian tentang dokumentasi sangat penting untuk dilakukan karena merupakan masalah global yang sangat mempengaruhi kualitas pelayanan kesehatan. Hasil penelitian Balang et al. (2017), yang bertujuan untuk mengeksplorasi praktik keperawatan di Malaysia juga menerangkan bahwa perawat tidak mampu mendokumentasikan asuhan dengan baik sehingga praktik keperawatan sebagai salah satu professional pemberi asuhan di rumah sakit memiliki kualitas yang kurang baik.

Gustina, dan Maryam (2015) di RS X, Jakarta, menyatakan bahwa mutu pelayanan yang masih rendah yang dicerminkan oleh pendokumentasian asuhan keperawatan belum lengkap dan tidak memenuhi standar asuhan keperawatan Departemen Kesehatan. Penelitian Sumilat (2017), tentang standar pendokumentasian asuhan keperawatan di BLUD RSUD Kota Baubau menjelaskan bahwa 
pendokumentasian asuhan keperawatan tidak berjalan secara optimal.

Penelitian Muryani, Pertiwiwati, dan Setiawan (2019) di RSUD

Kalimantan Tengah, juga menjelaskan bahwa kualitas pendokumentasian asuhan keperawatan tidak dapat meningkatkan mutu pelayanan di rumah sakit dengan hasil berkualitas hanya sebesar 55,9\%. Dokumentasi asuhan keperawatan telah diteliti pada berberapa kota di Indonesia, baik wilayah di Indonesia bagian barat maupun bagian tengah, akan tetapi untuk wilayah Indonesia bagian timur belum adanya penelitian terkait kualitas pendokumentasian asuhan keperawatan.

Hasil audit asuhan keperawatan ditemukan adanya masalah dalam dokumentasi asuhan keperawatan di RS X Kota Ambon. Observasi yang dilakukan di ruang rawat inap saat kegiatan residensi menunjukkan proses asuhan keperawatan telah dilakukan dengan baik oleh perawat pelaksana, tetapi untuk proses dokumentasi masih sangat kurang. Kelengkapan dokumentasi pada proses asuhan keperawatan kurang dari 50\%. Kegiatan pelatihan dokumentasi keperawatan yang diberikan kepada perawat tidak cukup untuk memperbaiki dampak negatif kualitas pelayanan, oleh karena itu peran manajer (kepala ruang) sebagai pemimpin staf perawat dalam mendokumentasikan asuhan keperawatan sangat penting untuk dilakukan (Okaisu, Kalikwani, Wanyana, \& Coetzee, 2014).

Penelitian Kamil, Rachmah, dan Wardani (2018) yaitu mengidentifikasi masalah pendokumentasian asuhan keperawatan di Indonesia. Penelitian ini menyatakan bahwa salah satu faktornya 


\section{METODE PENELITIAN}

adalah supervisi yang tidak memadai terhadap pendokumentasian asuhan keperawatan. Hasil audit saat kegiatan residensi juga menunjukkan supervisi kepala ruang sebagai first line manager di RS X Kota Ambon pada pendokumentasian asuhan keperawatan tidak optimal karena belum adanya pelatihan. Hasil penelitian Linggardini (2010) dan Widjayanti (2012), bahwa supervisi memiliki hubungan yang signifikan dengan dokumentasi, sehingga mempengaruhi perilaku perawat dalam mendokumentasikan asuhan. Hasil tersebut juga dipengaruhi oleh karakteristik perawat yaitu usia, tingkat pendidikan, dan beban kerja perawat. Sumaedi (2010), juga mengemukakan bahwa pelatihan supervisi adalah salah satu cara untuk meningkatkan dokumentasi asuhan keperawatan dengan memanfaatkan fungsi pengarahan dalam manajemen keperawatan.

Penelitian ini bertujuan untuk melakukan analisis dan interpretasi terhadap dokumentasi asuhan keperawatan oleh perawat pelaksana setelah pelatihan supervisi kepala ruang di Rumah Sakit X Kota Ambon

Penelitian ini menggunakan rancangan praeksperimenl one group pterest posttest design untuk mencari kemungkinan adanya peningkatan pendokumentasian asuhan keperawatan oleh perawat pelaksana setelah pelatihan supervisi kepala ruang.

Populasi dalam penelitian ini adalah semua perawat yang bekerja di Ruang rawat inap Rumah Sakit X Ambon, berjumlah 42 orang perwat pelaksana dengan teknik pengambilan sampel yang digunakan yaitu total sampling. Total sampel dalam penelitian ini berjumlah 40 responden karena terdapat dua responden yang masuk 
kedalam kriteria eksklusif yaitu responden yang tidak berada pada saat penelitian dilakukan.

Pengumpulan data dilaksanakan pada bulan Februari - Maret 2020 di Rumah Sakot X Kota Ambon dengan menerapkan prinsipprinsip etik penelitian. Instrument pengumpulan data menggunakan instrument bagian A yaitu kuesioner penelitian yang memuat karakteristik perawat yang termasuk dalam variabel confounding. Instumen bagian B adalah lembar observasi tentang pendokumentasian asuhan keperawatan. Prosedur pengumpulan data yaitu; pada minggu pertama untuk melihat fenomena digunakan lembar observasi. Minggu kedua, kemudian dilakukan intervensi berupa pelatihan supervisi kepala ruang untuk menerapkan pendokumentasian asuhan keperawatan khusus klien dewasa umum ruang rawat inap Rumah Sakit $\mathrm{X}$ Kota Ambon. Pada minggu ketiga dimana intervensi telah dilakukan, peneliti melakukan pendampingan pada kepala ruang untuk mengimplementasikan supervisi terhadap pendokumentasian asuhan keperawatan oleh perawat pelaksana. Minggu keempat, kelima, dan keenam, peneliti melakukan observasi mingguan untuk mengetahui apakah ada perubahan pada pendokumentasian asuhan keperawatan oleh perawat pelaksana di ruang rawat inap Rumah Sakit X Kota Ambon. Pada tahap akhir dilakukan post test pada minggu ketujuh, selanjutnya dilakukan analisa data.

Analisis bivariat dengan menggunakan uji Wilcoxon untuk menganalisis perbedaan perubahan pendokumentasian asuhan 
HASIL DAN

\section{PEMBAHASAN}

keperawatan oleh perawat pelaksana di ruang rawat inap Rumah Sakit

X Kota Ambon sebelum dan sesudah intervensi pelatihan supervisi kepala ruang, sedangkan uji Chi Square untuk menganalisis pengaruh usia, jenis kelamin, tingkat pendidikan dan lama kerja terhadap perubahan pendokoumentasian asuhan keperawatan oleh perawat pelaksana di ruang rawat inap Rumah Sakit X Kota Ambon.

Tabel 1. Distribusi Frequensi Karakteristik Responden

\begin{tabular}{lcc}
\hline \multicolumn{1}{c}{ Variabel } & $\mathrm{n}$ & $\%$ \\
\hline Usia & 31 & $77.5 \%$ \\
20-40 tahun & 9 & $22.5 \%$ \\
40-60 tahun & & \\
\hline Jenis Kelamin & 7 & $17.5 \%$ \\
Laki-Laki & 33 & $82.5 \%$ \\
Perempuan & & \\
\hline Tingkat Pendidikan & 33 & $82.5 \%$ \\
D3/S1 Keperawatan & 7 & $17.5 \%$ \\
Nurse & & \\
\hline Lama Kerja & 14 & $35 \%$ \\
$<6$ Tahun & 26 & $65 \%$ \\
$\geq 6$ Tahun & & \\
\hline
\end{tabular}

(Sumber: Data Primer, 2020)

Responden terbanyak berada pada rentang usia 20-40 tahun $77.5 \%$, jenis kelamin $82,5 \%$ responden dari total 40 responden. Pendidikan D3/S1 Keperawatan 82,5\%, dan lama kerja menunjukkan bahwa mayoritas responden berada pada rentang lama kerja lebih dari 6 tahun $65 \%$. 
Tabel 2. Distribusi Frekuensi Penerapan Supervisi

\begin{tabular}{ccccc}
\hline Supervisi & Minggu 1 & Minggu 2 & Minggu 3 & Minggu 4 \\
\hline Tidak Dilakukan & $0 \%$ & $0 \%$ & $0 \%$ & $0 \%$ \\
Dilakukan 1 kali/minggu & $20 \%$ & $20 \%$ & $40 \%$ & $60 \%$ \\
Dilakukan >1 kali/minggu & $80 \%$ & $80 \%$ & $60 \%$ & $40 \%$ \\
\hline Total & $100 \%$ & $100 \%$ & $100 \%$ & $100 \%$ \\
\hline
\end{tabular}

(Sumber: Data Primer, 2020)

Tabel 2 menunjukkan bahwa semua kepala ruang melakukan penerapan supervisi setelah dilakukannya pelatihan. Persentase terbesar pada minggu pertama dan kedua yaitu $80 \%$ kepala ruang yang melakukan penerapan supervisi lebih dari sekali dalam seminggu. Pada minggu ketiga dan keempat terjadi penurunan yaitu $60 \%$ dan $40 \%$ kepala ruang yang melakukan penerapan supervisi lebih dari sekali dalam seminggu.

Tabel 3. Distribusi Frekuensi Pendokumentsian Asuhan Keperawatan

\begin{tabular}{lcccc}
\hline \multirow{2}{*}{ Pendokumentasian } & \multicolumn{2}{c}{ Sebelum Intervensi } & \multicolumn{2}{c}{ Sesudah Intervensi } \\
\cline { 2 - 5 } & $\mathrm{n}$ & $\%$ & $\mathrm{n}$ & $\%$ \\
\hline Pengkajian & & & & \\
Baik & 12 & $30 \%$ & 38 & $95 \%$ \\
Kurang Baik & 28 & $70 \%$ & 2 & $5 \%$ \\
\hline Diagnosis & & & & \\
Baik & 0 & $0 \%$ & 22 & $55 \%$ \\
Kurang Baik & 40 & $100 \%$ & 18 & $45 \%$ \\
\hline Intervensi & & & & \\
Baik & 32 & $80 \%$ & 38 & $95 \%$ \\
Kurang Baik & 8 & $20 \%$ & 2 & $5 \%$ \\
\hline Implemetasi & & & & \\
Baik & 0 & $0 \%$ & 29 & $72.5 \%$ \\
Kurang Baik & 40 & $100 \%$ & 11 & $27.5 \%$ \\
\hline Evalusi & & & & \\
Baik & 0 & $0 \%$ & 25 & $62.5 \%$ \\
Kurang Baik & 40 & $100 \%$ & 15 & $37.5 \%$ \\
\hline
\end{tabular}


Tabel 3 menunjukkan pendokumentasian asuhan keperawatan sebulum intervensi menunjukkan persentase terbesar tahap pengkajian, diagnosis, implementasi dan evaluasi kurang baik, sedangkan tahap intervensi baik. Hal ini menunjukkan setelah dilakukan intervensi yaitu pelatihan kemudian diikuti dengan pendampingan kepala ruang, terlihat peningkatan jumlah responden dalam pendokumentasian asuhan keperawatan dari kurang baik menjadi baik pada tahap pengkajian, diagnosis, intervensi, implementasi, dan evaluasi. Menurut American Nursing Assication (ANA) supervisi sebagai proses aktif mengarahkan, memandu, memengaruhi hasil kinerja kearah positif sesuai dengan standar yang diharapkan dimana dapat dilakukan oleh seorang manager terhadap staf perawat (McEachen \& Keogh, 2018).

abel 4. Skor Pendokumentasian Asuhan Keperawatan oleh Perawat Pelaksana Sebelum dan Sesudah Intervensi

\begin{tabular}{lccc}
\hline \multirow{2}{*}{ Variabel } & \multicolumn{2}{c}{ Selisih Skor Peningkatan } & \multirow{2}{*}{$\begin{array}{c}\text { Sig. P value Wilcoxon } \\
\%\end{array}$} \\
\cline { 2 - 3 } & Mean & $\%$ & 0.000 \\
\hline Pengkajian & 2.1 & $23 \%$ & 0.000 \\
\hline Diagnosis & 2.35 & $39 \%$ & 0.000 \\
\hline Intervensi & 0.9 & $15 \%$ & 0.000 \\
\hline Implementasi & 1.75 & $44 \%$ & 0.000 \\
\hline Evaluasi & 2.5 & $42 \%$ &
\end{tabular}

(Sumber: Data Primer, 2020)

Pada tabel 4 menunjukkan bahwa adanya peningkatan skor pendokumentasian asuhan keperawatan oleh perawat pelaksana sebelum dan setelah dilakukan intervensi dengan hasil $p=0.000$, dimana nilai $p<0.05$, berarti adanya perbedaan yang signifikan skor 
sebelum dan sesudah intervensi pada setiap variabel pengkajian, diagnosis, intervensi, implementasi, dan evaluasi.

Hasil penelitian ini membuktikan bahwa pelatihan supervisi kepala ruang yang disertai dengan satu minggu pendampingan saat implementasi supervisi di ruang perawatan bersama peneliti sangat efektif dalam pendokumentasian asuhan keperawatan. Hasil penelitian ini menunjukkan selisih skor peningkatan sebelum dan sesudah intervensi dengan prosentase pada tahap pengkajian 23\%, diagnosis $39 \%$, intervensi $15 \%$, implementasi $44 \%$, dan evaluasi $42 \%$. Hasil penelitian ini sejalan dengan Goziyan (2012) yang menunjukkan supervisi kepala ruang efektif dalam peningkatan pendokumentasian. Peningkatan prosentase sebelum dan sesudah intervensi pada tahap pengkajian $8.4 \%$, diagnosis $8.6 \%$, intervensi keperawatan $8.8 \%$, implementasi $12.6 \%$, dan evaluasi $6.2 \%$.

Hasil peneitian Lestari (2014), Simeulu (2013), Yanti dan Warsito (2013), Widjayanti (2012), serta Linggardani (2010), juga menyatakan bahwa supervisi memiliki hubungan yang signifikan dengan kinerja perawat dalam bentuk pendokumentasian asuhan keperawatan, dimana hal tersebut didukung oleh intensitas dalam melakukan supervisi secara teratur. Supervisi klinis oleh kepala ruang juga harus dipertahankan dan dilakukan secara teratur serta berkelanjutan, agar perawat pelaksana di ruang rawat inap dapat temotivasi dalam meningkatkan kinerjanya. Peningkatan pendokumentasian asuhan keperawatan dalam penelitian ini terjadi karena terjadinya diskusi yang interaktif antara seluruh staf manajer keperawatan di rumah sakit terkait petunjuk teknis asuhan keperawatan agar dibuat lebih 
terperinci sehingga menjadi dasar perawat pelaksana dalam melakukan pendokumentasian asuhan keperawatan.

Tabel 5. Hubungan antara Karakteristik Responden dengan Pendokumentasian Asuhan Keperawatan

\begin{tabular}{|c|c|c|c|c|c|c|c|}
\hline \multirow{3}{*}{ Variabel } & \multicolumn{6}{|c|}{ Pendokumentasian } & \multirow{3}{*}{$P$ value } \\
\hline & \multicolumn{2}{|c|}{ Tidak Meningkat } & \multicolumn{2}{|c|}{ Meningkat } & \multicolumn{2}{|c|}{ Total } & \\
\hline & $\mathrm{n}$ & $\%$ & $\mathrm{n}$ & $\%$ & $\mathrm{n}$ & $\%$ & \\
\hline \multicolumn{8}{|l|}{ Usia } \\
\hline 20-39 tahun & 2 & $6.5 \%$ & 27 & $93.5 \%$ & 31 & $100 \%$ & \multirow{2}{*}{1.928} \\
\hline 40-60 tahun & 2 & $22.2 \%$ & 7 & $77.8 \%$ & 9 & $100 \%$ & \\
\hline \multicolumn{8}{|l|}{ Jenis } \\
\hline \multicolumn{8}{|l|}{ Kelamin } \\
\hline Laki-laki & 0 & $0 \%$ & 7 & $100 \%$ & 7 & $100 \%$ & \multirow{2}{*}{0,943} \\
\hline Perempuan & 4 & $12.1 \%$ & 29 & $87.9 \%$ & 33 & $100 \%$ & \\
\hline \multicolumn{8}{|l|}{ Pendidikan } \\
\hline DIII/S1 & 3 & $9.1 \%$ & 30 & $90.9 \%$ & 33 & $100 \%$ & \multirow{2}{*}{0,173} \\
\hline Ns & 1 & $14.3 \%$ & 6 & $85.7 \%$ & 7 & $100 \%$ & \\
\hline \multicolumn{8}{|l|}{ Lama Kerja } \\
\hline$<6$ tahun & 1 & $7.1 \%$ & 13 & $92.9 \%$ & 14 & $100 \%$ & \multirow[t]{2}{*}{0,195} \\
\hline$\geq 6$ tahun & 3 & $11.5 \%$ & 23 & $88.3 \%$ & 26 & $100 \%$ & \\
\hline
\end{tabular}

(Sumber: Data Primer, 2020)

Tabel 5 menunjukkan hasil analisis hubungan usia, jenis kelamin, tingkat pendidikan, dan lama kerja dengan pendokumentasian asuhan keperawatan semua nilai $p>0.05$, berarti tidak adanya hubungan antara variabel perancu (confounding) usia, jenis kelamin, tingkat pendidikan, dan lama kerja dengan pendokumentasian asuhan keperawatan di Rumah Sakit X Kota Ambon.

Hasil penelitian ini selaras dengan beberapa penelitian sebelumnya yaitu Lestari (2014) menyatakan bahwa usia, pendidikan, dan masa kerja seorang perawat tidak memiliki hubungan yang signifikan dengan pendokumentasian asuhan keperawatan. Widjayanti (2012) juga dalam penelitiannya menyatakan tidak ada pengaruh yang 
signifikan antara jenis kelamin dengan dokumentasi asuhan keperawatan.

Pada penelitian ini terjadinya peningkatan pendokumentasian asuhan keperawatan menjadi lebih baik dipengaruhi oleh pelatihan supervisi kepala ruang dan pendampingan bersama peneliti selama satu minggu, dan minggu berikutnya kepala ruang melakukan supervisi mandiri tarhadap pendokumentasian asuhan keperawatan yang dilakukan oleh perawat pelaksana di ruang rawat inap. Sejalan dengan penelitian Yanti dan Warsito (2013) yang menyatakan bahwa pelatihan supervisi kepala ruang akan mempengaruhi kualitas pendokumentasian asuhan keperawatan dan tidak dipengaruhi oleh karakteristik perawat pelaksana seperti usia, pendidikan, jenis kelamin, dan masa kerja. Oleh karena itu, Supervisi klinis oleh kepala ruang harus dilakukan secara teratur serta berkelanjutan agar perawat pelaksana di ruang rawat inap dapat temotivasi dalam meningkatkan pendokumentasian yang berorientasi pada pelayanan asuhan keperawatan yang berkualitas. perempuan (82,5\%), pendidikan D3/S1 Keperawatan (82,5\%) dan lama kerja lebih dari 6 tahun (65\%). Skor pendokumentasian meningkat secara bermakna $(\mathrm{p}<0.050)$ setelah dilakukan pelatihan supervisi kepala ruang, dan pendampingan implementasi supervisi. Tidak ada hubungan antara antara umur $(p=1.926)$, Jenis kelamin $(p=0.943)$, Pendidikan $\quad(p=0.173)$, dan lama kerja $(p=0.195)$ dengan pendokumentasian asuhan keperawatan setelah pelatihan supervisi 
kepala ruang di Rumah Sakit X Kota Ambon.

Berdasarkan kesimpulan, saran atau rekomendari yang peneliti sampaikan sebagai berikut:

1. Bagi Pelayanan Keperawatan : Supervisi klinis oleh kepala ruang harus dilakukan secara teratur serta berkelanjutan agar perawat pelaksana di ruang rawat inap dapat temotivasi dalam meningkatkan pendokumentasian yang berorientasi pada pelayanan asuhan keperawatan yang berkualitas.

2. Bagi Pendidikan: Hasil penelitian ini dapat dijadikan referensi dalam penyususnan pembelajaran yang tepat terkait kepemimpinan dalam keperawatan khususnya fungsi perawat manajer sebagai pengarahan/penggerak.

3. Bagi Peneliti Selanjutnya : Perlunya dilakukan penelitian lebih lanjut tentang pendokumentasian asuhan keperawatan dengan desain penelitian yang menggunkan kelompok control atau kelompok pembanding, dengan jumlah responden yang lebih banyak.

\section{DAFTAR PUSTAKA}

Abu Sharour, L., Subih, M., Yehia, D., Suleiman, K., Salameh, A. B., \& Al Kaladeh, M. (2018). Teaching module for improving oncology nurses' knowledge and self-confidence about central line catheters caring, complications, and application: A pretestposttest quasi-experimental design. Journal of Vascular Nursing, 36(4), 203-207. https://doi.org/10.1016/j.jvn.2018.07.005

Akhu-Zaheya, L., Al-Maaitah, R., \& Bany Hani, S. (2018). Quality of nursing documentation: Paper-based health records versus electronic-based health records. Journal of Clinical Nursing, 27(34), e578-e589. https://doi.org/10.1111/jocn.14097.

Alkouri, Osama A., AlKhatib, Ahed J., Kawafhah, Mariam. (2016). 
Importance And Implementation Of Nursing Documentation: Review Study. European Scientific Journal January 2016 edition vol.12, No.3 ISSN: 1857 - 7881 (Print)e-ISSN1857-7431. https://eujournal.org/index.php/esj/article/download/6955/6671

Alligood, M. R. (2017). Pakar Teori Keperawatan dan Karya Mereka. Volume 1 Edisi Indonesia Ke-8. Jakarta: Elsevier

Amsrud, K. E., Lyberg, A., \& Severinsson, E. (2015). The influence of clinical supervision and its potential for enhancing patient safety Undergraduate nursing students' views. Journal of Nursing Education and Practice, 5(6), 87-95. https://doi.org/10.5430/jnep.v5n6p87

ANA. (2010). ANA's Principles for Nursing Documentation Guidance for Registered Nurses. Retrieved from http://www.Nursingworld.org. Diperoleh 18 Februari 2019.

. (2015). Scope and Standards of Practice: 3rd Edition. Retrieved from http://www.Nursingworld.org. Diperoleh 18 Februari 2019.

Asamani, J. A., Amenorpe, F. D., Babanawo, F., \& Ofei, A. M. A. (2014). Nursing documentation of inpatient care in eastern Ghana. British Journal of Nursing, 23(1), 48-54. https://doi.org/10.12968/bjon.2014.23.1.48

Balang, R. V., Burton, R. L., \& Barlow, N. A. (2017). Illuminating professionalism among nurses in their documentation within the Malaysia context - A qualitative stuDY. International Journal of Business and Society, 18(S4), 692-700.

Brunero, S., \& Stein-Prabury, J. (2008). The effectiveness of clinical supervision in nursing : an evidenced based literature review Authors. Scholary Paper, 25(3), 86-94.

Compton, E. K., Gildemeyer, K., Mason, T. M., Hartranft, S. R., \& Sutton, S. K. (2018). Nurses' Caring Behaviors. Clinical Journal of Oncology Nursing, 22(2), 169-174. 
Compton, E. K., Gildemeyer, K., Reich, R. R., \& Mason, T. M. (2019). Perceptions of caring behaviours: A comparison of surgical oncology nurses and patients. Journal of Clinical Nursing, 33612, 0-1. https://doi.org/10.1111/jocn.14773

Christensen, Paula J. \& Kenney, Janet W. (2009). Proses Keperawatan: Aplikasi Model Konseptual. Ed. 4. EGC: Jakarta.

Creswell, Jhon W. (2017). Research Design. Pendekatan Metode Kualitatif, Kuantitatif, dan Campuran, Edisi 4. Yogyakarta: Pustaka Pelajar.

Friyanti, E. S. (2015). Analisis Kualitas dan Kuantitas Tenaga Keperawatan Terhadap Persepsi Insiden Keselamatan Pasien. Jurnal Administrasi Rumah Sakit 2 (1): 43-52

Girling, A., Leese, C., \& Maynard, L. (2009). How clinical supervision can improve hospice care for children. Nursing Management (Harrow, London, England:1994), 20-23. https://doi.org/10.7748/nm2009.11.16.7.20.c7350

Goncalves, S. A., Strong, L. L., \& Nelson, M. (2016). Measuring nurse caring behaviors in the hospitalized older adult. Journal of Nursing Administration, 46(3), 132-138. https://doi.org/10.1097/NNA.0000000000000312

Goziyan. (2012). Efektivitas Penerapan Supervisi Kepala Ruang terhadap Pelaksanaan Pendokumentasian Asuhan Keperawatan di Ruang Rawat Inap Rumah Sakit PKU Muhammadiyah. Tesis Program Pascasarjana Universitas Muhammadiyah: Yogyakarta.

Hartati, Sri. (2010). Kualitas Dokumentasi Asuhan Keperawatan Di Ruang Rawat Inap RS PKU Muhammadiyah Yogyakarta. Skripsi Program Studi IImu Keperawatan Sekolah Tinggi Ilmu Kesehatan 'Aisyiyah: Yogyakarta.

Hsu, T.-C., Chiang-Hanisko, L., Lee-Hsieh, J., Lee, G.-Y., Turton, M. A., \& Tseng, Y.-J. (2015). Effectiveness of an Online Caring Curriculum 
in Enhancing Nurses' Caring Behavior. The Journal of Continuing Education in Nursing, 46(9), 416-424. https://doi.org/10.3928/00220124-20150821-04.

Kamil, Hajjul.. Rachmah, R., Wardani, Elly. (2018). What is the Problem with Nursing Documentation? Perspective of Indonesian Nurses. International Journal of Africa Nursing Sciences 9 (2018) 111-114. https://www.sciencedirect.com/science/article/pii/S2214139117 301208

Ilyas, Yaslis. (2002). Kinerja: Teori, Penilaian, Penelitian. Depok: Fakultas Kesehatan Masyarakat Universitas Indonesia.

Jefferies, D., Johnson, M., \& Griffiths, R. (2010). A meta-study of the essentials of quality nursing documentation. International Journal of Nursing Practice, 16(2), 112-124. https://doi.org/10.1111/j.1440-172X.2009.01815.x

Kamus Besar Bahasa Indonesia (KBBI) Online.

Kementrian Kesehatan Republik Indonesia (2018). Profil Kesehatan Indonesia Tahun 2017. http://www.kemkes.go.id/. Diperoleh 18 Maret 2019.

Kent, P., \& Morrow, K. (2014). Better documentation improves patient care. Nursing Standard, 29(14), 44-51. https://doi.org/10.7748/ns.29.14.44.e9267

Kurniadi, Anwar. (2016). Manajemen Keperawatan dan Prospektifnya, Teori, Konsep dan Aplikasi. Jakarta: Fakutas Kedokteran Universitas Indonesia.

KARS (Komite Akreditasi Rumah Sakit). (2017). Standar Nasional Akreditasi Rumah Sakit Edisi 1. In Komisi Akreditasi Rumah Sakit (pp. 1-421). https://doi.org/362.11

Kozier, Barbara., Erb, Glenor., Berman, Audrey., Snyder, Shirlee J. (2011). Buku Ajar Fundamental Keperawatan: Konsep, Proses, 
dan Praktik. EGC: Jakarta.

Lestari, N. W. (2014). Pengaruh Supervisi Metode Klinis Terhadap Kelengkapan Dokumentasi Asuhan Keperawatan di RSUD . H Soewondo Kendal. Jurnal IImu Keperawatan dan Kebidanan (JIKK) STIKES Telogorejo Volume 3. http://ejournal.stikestelogorejo.ac.id/index.php/ilmukeperawata n/article/view/231/256

Linggardini, Kris. (2010). Hubungan Supervisi dangan Pendokumentasian Berbasis Komputer yang Dipresepsikan Perawat Pelaksana di Instalasi Rawat Inap RSUD Banyumas, Jawa Tengah. Tesis Fakultas IImu Keperawatan Universitas Indonesia: Jakarta.

Marquis, Bessie L., Huston, Carol J. (2016). Kepemimpinan dan Manajemen Keperawatan, Teori dan Aplikasi. Edisi 4. Jakarta: EGC.

McEachen, Irene \& Keogh, Jim. (2018). Manajemen Keperawatan, DeMYSTiFieD. Buku Wakib Bagi Praktisidan Mahasisw Keperawatan. Jogjakarta: ANDI.

Muryani, Pertiwiwati, Endang., Setiawan, Herry. (2019). Kualitas Pendokumentasian Asuhan Keperawatan Di Ruang Rawat Inap (Studi Di Rsud Kalimantan Tengah). Nerspedia, April 2019; 2(1): 27-32.

http://jtam.ulm.ac.id/index.php/nerspedia/article/download/184 /96/.

Nakate, G. M., Dahl, D., Petrucka, P., B. Drake, K., \& Dunlap, R. (2015). The Nursing Documentation Dilemma in Uganda: Neglected but Necessary. A Case Study at Mulago National Referral Hospital. Open Journal of Nursing, 05(12), 1063-1071. https://doi.org/10.4236/ojn.2015.512113

Nursalam. (2008). Konsep dan Penerapan Metodologi Penelitian IImu Keperawatan. Pedoman Skripsi, Tesis, dan Instrumen Penelitian 
Keperawatan. Edisi 2. Jakarta: Salemba Medika.

. (2016). Manajemen Keperawatan, Aplikasi dalam Praktik Keperawatan Profesional. Edisi 5. Jakarta: Salemba Medika.

Noorkasiani, Gustina, Maryam, R. Siti. (2015). Faktor-Faktor yang Berhubungan dengan Kelengkapan Dokumentasi Keperawatan. Jurnal Keperawatan Indonesia, Volume 18 No.1, Maret 2015, hal 1-8 pISSN 1410-4490, eISSN 2354-9203. http://jki.ui.ac.id/index.php/jki/article/view/391/504.

Novitarum, Lisis. (2013). Pengembangan Audit Dokumentasi Keperawatan di Raung Perawatan Intensif di Rumah Sakit Santa Elisabeth Medan. Tesis Fakultas IImu Keperawatan Universitas Sumatera Utama: Sumatera.

Okaisu, E. M., Kalikwani, F., Wanyana, G., \& Coetzee, M. (2014). Improving the quality of nursing documentation: An action research project. Curationis, 37(2), 1-11. https://doi.org/10.4102/curationis.v37i2.1251

Olfah, Y., \& Ghofur, A. (2016). Dokumentasi Keperawatan: Modul Bahan Ajar Cetak Keperawatan. Jakarta Selatan: Pusdik SDM Kesehatan.

PPNI. (2017). Standar Diagnosa Keperawatan Indonesia: Definisi dan Indikator Diagnostik. Jakarta. - (2018). Standar Intervensi Keperawatan Indonesia: Definisi dan Tindakan Keperawatan. Jakarta.

Potter, Patricia A. \& Perry, Anne Griffin. (2005). Buku Ajar Fundamental Keperawatan: Konsep, Proses, dan Praktik, Volume 1, Edisi 4. Jakarta: EGC.

Purwanti, Eka Desi. (2012). Kelengkapan Dokumentasi Asuhan Keperawatan dan Karakteristiknya Pada Pasien Rawat Inap Dewasa Non Kebidanan di Rumah Sakit Haji Jakarta Tahun 2012. Skripsi Fakultas Kesehatan Masyarakat Universitas Indonesia: 


\section{Depok.}

Putra, Candra Syah. (2016). Buku Ajar Manajemen Keperawatan; Teori dan Aplikasi Dilengkapi Dengan Kuisioner Pengkajian Praktek Manajemen Keperawatan. In Media: Jakarta.

Robbins, Stephen P. \& Judge, Thimoty A. (2015). Perilaku Organisisai. Salemba Empat: Jakarta.

Ross, M. (2013). Implementing clinical supervision in mental health practice. Mental Health Practice, 17(2), 34-39.

Simeulu, Putro. (2013). Efektivitas Pelatihan Supervisi Klinik Kepala Ruangan terhadap Kinerja Perawat Pelaksana di Ruang Rawat Inap RSUD dr.H.Yuliddin Away Tapaktuan Kabupaten Aceh Selatan. Tesis Fakultas IImu Keperawatan Universitas Sumatera Utama: Sumatera.

Sitorus, Ratna \& Panjaitan, Rumondang. (2011). Manajemen Keperawatan: Manajemen Keperawatan di Ruang Rawat. Sagung Seto: Jakarta.

Suharsaputra, Uhar. (2012). Metode Penelitian: Kuantitatif, Kulaitatif, dan Tindakan. Refika Aditama: Bandung.

Sumilat, Niken Pradipta. (2017). Standar Pendokumentasian Asuhan Keperawatan di BLUD RSUD Kota Baubau. Skripsi Fakultas Kedokteran dan Ilmu Kesehatan Universitas Islam Negeri Alauddin: Makassar.

Swansburg, RC., 2000. Terjemahan Pengantar Kepemimpinan dan Manajemen Keperawatan untuk Perawat Klinis. Alih bahasa Agung Waluyo, Yasmin Asih. EGC: Jakarta.

Undang Undang Republik Indonesia No. 36 Tahun 2009 tentang Kesehatan.

Undang Undang Republik Indonesia No. 20 Tahun 2003 tentang Sistem 
Pendidikan Nasional.

Undang Undang Republik Indonesia No. 24 Tahun 2013 tentang Administrasi Kependudukan.

Undang Undang Republik Indonesia No. 44 Tahun 2009 tentang Rumah Sakit

Undang Undang Republik Indonesia No. 38 Tahun 2014 tentang Keperawatan

Vafaei, S. M., Manzari, Z. S., Heydari, A., Froutan, R., \& Farahani, L. A. (2018). Nurses' perception of nursing services documentation barriers: a qualitative approach. Electronic Journal of General Medicine, 15(3), 3-10. https://doi.org/10.29333/ejgm/86184

Wang, N., Hailey, D., \& Yu, P. (2011). Quality of nursing documentation and approaches to its evaluation: A mixed-method systematic review. Journal of Advanced Nursing, 67(9), 1858-1875. https://doi.org/10.1111/j.1365-2648.2011.05634.x

Widjayanti, Trisna Budy. (2012). Hubungan atrara Karakteristik Individu, Psikologis, dan Organisasi, dengan Perilaku Pendokumentasian Asuhan Keperawatan Unit Rawat Inap RS. MH. Thamrin Purwakarta Tahun 2011. Tesis Fakultas IImu Keperawatan Universitas Indonesia: Jakarta.

Yanti, Retyaningsih Ida dan Warsito, Bambang Edi. (2013). Hubungan Karakteristik Perawat, Motivasi, dan Supervisi Dengan Kualitas Dokumentasi Proses Asuhan Keperawatan. Jurnal Managemen Keperawatan. Volume 1, No. 2, November 2013; 107-114. https://jurnal.unimus.ac.id/index.php/JMK/article/download/100 6/1055. 